\title{
Impactos da estrutura etária sobre 0 desempenho econômico das regiões do Brasil entre 1991 e 2010
}

\author{
Marianne Zwilling Stampe* \\ Fernando Pozzobon ${ }^{* *}$ \\ Thais Waideman Niquito**
}

Este estudo objetiva analisar como a estrutura etária afetou o desempenho econômico das regiões brasileiras nas décadas de 1990 a 2010. Para a investigação proposta, são usadas, principalmente, as informações disponibilizadas pelo Instituto Brasileiro de Geografia e Estatística (IBGE) nas edições de 1991, 2000 e 2010 do Censo Demográfico. A estratégia empírica adotada consiste na estimação de um modelo de autocorrelação espacial pelo método de mínimos quadrados em dois estágios espaciais. Os resultados mostraram que tanto a razão de dependência infantil quanto a de idosos possuem impacto negativo sobre o crescimento econômico, sendo que os efeitos são mais acentuados nas regiões menos desenvolvidas. Ainda, observou-se que, quando significativo, o efeito da razão de dependência de idosos é mais acentuado em relação à infantil.

Palavras-chave: Transição demográfica. Crescimento econômico. Regiões brasileiras.

\footnotetext{
*Universidade do Estado de Santa Catarina (Udesc), Florianópolis-SC, Brasil (marianne.stampe@udesc.br; https://orcid. org/0000-0002-5633-0370).

** Universidade do Estado de Santa Catarina (Udesc), Florianópolis-SC, Brasil (fernando.pozzobon@udesc.br; https:// orcid.org/0000-0003-1227-129X).

${ }^{\star \star \star}$ Universidade do Estado de Santa Catarina (Udesc), Florianópolis-SC, Brasil (thais.niquito@udesc.br; https://orcid. org/0000-0002-9527-4199).
} 


\section{Introdução}

Ao longo do século passado o Brasil, seguindo a tendência mundial, iniciou seu processo de transição demográfica, caracterizado majoritariamente pela redução nas taxas de mortalidade seguida por uma queda nas taxas de fecundidade. Este fenômeno tem como principais consequências o declínio da taxa de crescimento populacional e o envelhecimento da população, acarretando profundas alterações na estrutura etária do país (LUNDQUIST; ANDERTON; YAUKEY, 2014; TEJADA et al., 2017).

De acordo com os dados dos Anuários Estatísticos do Brasil, disponibilizados pelo Instituto Brasileiro de Geografia e Estatística (IBGE), a mortalidade infantil brasileira para crianças com menos de 1 ano de idade - reduziu-se de pouco menos de 120 óbitos por mil nascidos vivos em 1960 para cerca de 29 em 2010. No mesmo período, a taxa de fecundidade total passou de aproximadamente seis filhos por mulher para pouco menos de dois filhos, sendo que a queda acentuou-se a partir da década de 1990. Por conseguinte, observou-se uma contração na taxa média de crescimento populacional, que passou de 2,9\% ao ano, entre 1960 e 1970, para 1,2\% ao ano, de 2000 a 2010.

0 consequente envelhecimento da população e as alterações na estrutura etária podem ser observados por meio das mudanças na razão de dependência (RD). Esta é caracterizada como a relação entre a soma do número de crianças (indivíduos de até 14 anos de idade) e de idosos (com 65 anos ou mais) e o número de pessoas em idade potencialmente ativa (15 a 64 anos), usualmente medida em termos percentuais. ${ }^{1}$ No Brasil, a razão de dependência diminuiu de 83,91\% em 1960 para 47,13\% em 2010. Quando dividida entre a RD infantil (relação entre as crianças e as pessoas de 15 a 64 anos de idade) e a RD dos idosos (relação entre os idosos e as pessoas com 15 a 64 anos), nota-se que a queda deveu-se, exclusivamente, à redução da participação das crianças na população. A proporção de crianças entre as pessoas em idade potencialmente ativa caiu de $78,68 \%$ para $35,15 \%$ no período, enquanto a de idosos aumentou de 5,23\% para $11,98 \%$. 0 índice de idosos, ou seja, o quociente entre o número de idosos e de crianças aumentou de 6,64\% em 1960 para 34,09\% em 2010.

É inegável, portanto, que o processo de transição demográfica esteja em marcha no país. Os dados de projeções populacionais, também disponibilizados pelo IBGE, mostram que este deve se intensificar ao longo das próximas décadas. É estimado que a RD tenha se reduzido até 2017 , quando chegou a 43,98\%. Desde então, dado o expressivo aumento no número de idosos, esta passou a aumentar. Projeta-se que, em 2060, a RD alcance $67,23 \%$, com RD infantil de $24,61 \%$ e a de idosos de $42,62 \%$. Ainda, espera-se que 0 número de idosos, em 2039, supere o de crianças na população brasileira. Em 2060, o índice de idosos é projetado em 173,17.

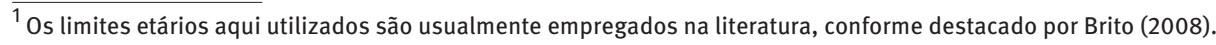


Há uma grande variabilidade nas circunstâncias motivadoras desse fenômeno, e identificar as causas implícitas ao processo em uma determinada região não é uma tarefa trivial. Entre os aspectos subjacentes à transição demográfica, a literatura destaca as profundas mudanças observadas na vida social devido aos processos de urbanização e de industrialização das economias. Este último, por exemplo, ao demandar aprimoramento do capital humano, pode ter alterado as decisões das famílias, que passaram a investir mais na formação dos filhos, priorizando a "qualidade" versus a "quantidade" de crianças, com uma consequente redução das taxas de fecundidade (BECKER; CINNIRELLA; WOESSMANN, 2010; GALOR; MOAV, 2002).

Entre outros motivos que explicam o processo de transição demográfica, estão os avanços das inovações médicas e dos programas de saúde pública e a ampliação do acesso ao saneamento básico (ALVES, 2008). Ainda, uma parte da literatura coloca entre as causas deste fenômeno as modificações no papel dos gêneros na sociedade. Zuanazzi, Bandeira e Stampe (2014) e Reis, Barbosa e Pimentel (2016), por exemplo, destacam a difusão dos métodos contraceptivos e o ingresso das mulheres no mercado de trabalho como elementos importantes deste processo.

O declínio das taxas de fecundidade, com consequentes alterações na composição da estrutura etária da população, resulta, em um primeiro momento, em aumento da participação da força de trabalho na população e da produtividade (GALOR, 2012). Assim, os processos de transição demográfica têm profundas implicações sobre as dinâmicas econômica, social e política locais (MISRA, 2015). Conforme destacam Prskawetz et al. (2007) e Fent, Mahlberg e Prskawetz (2008), fatores demográficos importam na análise de crescimento econômico tanto quanto, ou mais, aqueles usualmente explorados na literatura, como a mudança tecnológica, a inovação, as instituições, entre outros. Para os autores, os aspectos demográficos de uma sociedade afetam sua produtividade por meio de impactos na poupança, nos investimentos, na formação de capital humano, nas inovações tecnológicas, entre diversos outros.

Ainda, conforme destacado por Bloom, Canning e Fink (2010), à medida que os idosos passam a representar uma parcela cada vez mais significativa da população, serão necessários diversos ajustes, como, por exemplo, nos sistemas previdenciários, nos financiamentos dos gastos com saúde e nas políticas que visem a promoção da produtividade da mão de obra. Ou seja, o processo implica significativas alterações nos sistemas econômicos locais.

Como visto, a transição demográfica decorre da combinação de uma série de condições. Consequentemente, conforme destacam Lundquist, Anderton e Yaukey (2014), os processos de transição demográfica podem ocorrer de maneira bastante heterogênea entre regiões que possuem diferentes níveis de desenvolvimento no que tange a aspectos econômicos e sociais. Sabidamente, o Brasil possui acentuadas idiossincrasias ao longo de seu território, que se refletem em assimetrias nas estruturas demográficas observadas a partir das regiões (PORSSE et al., 2012). Estas podem ser entendidas como consequências dos 
diferentes processos históricos regionais de desenvolvimento, industrialização e urbanização (VASCONCELOS; GOMES, 2012).

A partir dos dados extraídos do Censo de 2010, por exemplo, pode-se observar que, enquanto as regiões Centro-Oeste, Sul e Sudeste apresentavam razões de dependência total menores do que aquela registrada para o país (44,95\%, 44,05\% e 43,85\%, respectivamente), no Norte e Nordeste estas eram significativamente maiores do que a média nacional $(56,72 \%$ e $51,89 \%$, respectivamente). Em ambos os casos, os diferenciais se devem, majoritariamente, à diferença nas razões de dependência infantil.

A literatura aponta para a existência de uma forte relação entre desenvolvimento e fecundidade (BAERLOCHER; PARENTE; RIOS-NETO, 2019; TEJADA et al., 2017), de modo que as heterogeneidades acima mencionadas podem ser explicadas pelos diferentes níveis de desenvolvimento observados entre as regiões do Brasil. Como indicam os dados do Atlas do Desenvolvimento Humano de $2013,244,1 \%$ dos municípios do Norte e $62,0 \%$ daqueles do Nordeste podem ser considerados de níveis de desenvolvimento baixo ou muito baixo. Nas regiões Centro-Oeste, Sul e Sudeste, estes percentuais são significativamente menores $(2,1 \%, 4,4 \%$ e $0,4 \%$, respectivamente). Não surpreendentemente, as taxas de fecundidade total são maiores nas duas primeiras regiões (2,4 filhos por mulher no Norte e 2,02 no Nordeste, em 2010) em relação ao observado nas três últimas (1,83 no CentroOeste e 1,70 no Sul e Sudeste, em 2010).

Em função dos potenciais efeitos da transição demográfica sobre diversos aspectos socioeconômicos, bem como da perspectiva de aprofundamento de tal processo no Brasil no decorrer deste século - em que se observará, principalmente, o aumento do percentual de idosos na população -, a investigação de como a participação das crianças e dos idosos impacta o crescimento econômico do país se mostra absolutamente relevante. Dadas as já mencionadas idiossincrasias territoriais, a análise segmentada por regiões é bastante pertinente. Esta é a proposta da presente pesquisa.

O objetivo central deste estudo é mensurar o efeito da RD das crianças e dos idosos sobre o desempenho econômico regional. Mais especificamente, são estimados, para cada uma das cinco regiões brasileiras, os efeitos das razões de dependência supracitadas sobre o crescimento da renda per capita das localidades, a partir de um modelo autorregressivo espacial - que considera defasagem espacial na variável dependente - pelo método de mínimos quadrados em dois estágios espaciais.

A análise é segmentada entre a magnitude da RD infantil e da RD de idosos, tendo em vista que o elemento causador de uma elevada razão de dependência é de extrema importância para a dinâmica econômica local e também para as implicações em termos de proposição de políticas. A literatura indica que ambas têm efeitos negativos sobre o crescimento econômico, embora os efeitos sejam mais robustos para os impactos da RD infantil (FUKUDA; MOROZUMI, 2004; KELLEY; SCHMIDT, 2005; PRSKAWETZ et al., 2007).

\footnotetext{
$\overline{2}$ Mais informações disponíveis em: http://atlasbrasil.org.br/2013/.
} 
Contudo, dado que o comportamento econômico dos indivíduos, bem como suas necessidades, varia nos diversos estágios da vida, diferenças na composição etária da população mudam a composição da oferta de trabalho, da demanda e da oferta de capital e também alteram a demanda por tipos de bens e serviços. Conforme destacado por Misra (2015), pessoas em diferentes grupos etários se comportam de maneira diferente, o que gera consequências econômicas diferentes. Por exemplo, uma maior RD causada por uma proporção superior de crianças evidencia a necessidade de investimentos em educação e treinamento para o mercado de trabalho, enquanto uma maior RD causada por uma proporção mais elevada de idosos destaca a necessidade de investimentos em saúde e de gastos com previdência (FENT; MAHLBERG; PRSKAWETZ, 2008).

A estratégia empírica adotada teve como base o crescente consenso na literatura de que as taxas de crescimento regional possuem dependência espacial. Os efeitos de transbordamento entre localidades espacialmente vizinhas podem ocorrer por meio de diversos canais. Por exemplo, quando uma determinada economia cresce - seja uma região, uma área metropolitana, um município -, o aumento que será observado na demanda por bens e serviços, por poupança e por fatores de produção dificilmente ficará circunscrito ao âmbito interno, sendo que seus vizinhos serão potencialmente afetados. Assim, diversos autores argumentam que o nível de renda de longo prazo de uma dada localidade depende não apenas de suas características próprias, mas também daquelas de seus vizinhos e do seu nível de conectividade com os mesmos. Consequentemente, em análises voltadas para a temática de crescimento regional, é importante que se contabilize explicitamente a dependência espacial (SILVEIRA NETO; AZZONI, 2006; LESAGE; FISCHER, 2008; CAPELLO, 2009; RESENDE, 2011; ÖZYURT; DAUMAL, 2013; LIMA; SILVEIRA NETO, 2016; LIMA; BARBOSA, 2019).

Os principais resultados da pesquisa indicaram que a RD infantil impactou negativamente o crescimento da renda em todas as regiões do país, com efeitos mais expressivos naquelas menos desenvolvidas. Já no caso da RD de idosos, os coeficientes se mostraram significativos apenas nas regiões Norte, Nordeste e Centro-Oeste, o que pode ser um indicativo de que o envelhecimento populacional afeta mais intensamente as localidades mais vulneráveis em termos de desenvolvimento. Por fim, destaca-se que, quando estatisticamente significativos, os efeitos negativos da RD de idosos superam os efeitos negativos da RD infantil.

Esta pesquisa tem, portanto, duas principais contribuições acerca de como o processo de transição demográfica afeta o crescimento econômico regional no Brasil. Primeiramente, a investigação em nível regional contribui ao verificar se as heterogeneidades observadas ao longo do território nacional resultam em efeitos diferentes dos aspectos demográficos sobre o crescimento. A segunda contribuição tem relação com a estratégia empírica adotada. A utilização de modelos espaciais permite que sejam contabilizados, nos efeitos estimados, os transbordamentos regionais existentes. Espera-se que o presente trabalho possa subsidiar estudos na proposição de políticas públicas que atendam às necessidades 
geradas a partir das transformações populacionais em marcha no país, em especial quanto à produtividade da população economicamente ativa, à projeção de impostos e à contribuição previdenciária.

0 artigo apresenta mais cinco seções além desta introdução. A segunda consiste em uma breve revisão da literatura que relaciona a transição demográfica ao crescimento econômico. A terceira mostra a estratégia empírica utilizada, detalhando as bases de dados empregadas e o modelo a ser estimado. A quarta faz a análise espacial das variáveis investigadas, evidenciando a adequabilidade do método escolhido. A quinta traz os resultados das estimativas, discutindo os efeitos obtidos. Por fim, são apresentadas as considerações finais.

\section{Transição demográfica e crescimento econômico}

A literatura sobre crescimento econômico, há longa data, relaciona a evolução da população com o desempenho econômico (por exemplo, JONES; VOLLRATH, 2016). Conforme mencionado por Prskawetz et al. (2007), grande parte dos estudos desenvolvidos ao longo da década de 1990 mostrou que o crescimento da população não possuía qualquer efeito sobre o crescimento econômico. Um dos motivos para tal comportamento é o fato de que se assumia, implicitamente, uma composição populacional etária constante. Ao se considerarem as mudanças na estrutura etária da população, postas em marcha pelos processos de transição demográfica observados globalmente, foi possível verificar que os aspectos demográficos possuem influência sobre o desempenho econômico. Dessa forma, a discussão relativa às causas e implicações da transição demográfica ganhou corpo nos anos mais recentes (PAIVA; WAJNMAN, 2005).

Há consenso na literatura de que o processo de transição demográfica ocorre em etapas. Em geral, destacam-se três marcadas fases, cujas distinções se dão pelas estruturas etárias observadas na sociedade ao longo do tempo. Em um primeiro momento, ocorre uma queda nas taxas de mortalidade e os níveis de fecundidade permanecem altos, o que acarreta crescimento acelerado da população e uma elevada participação de crianças, movimentos que se refletem em grandes razões de dependência. Posteriormente, além da queda das taxas de mortalidade, observa-se também redução nas taxas de fecundidade. Como consequência, há desaceleração do crescimento populacional e a razão de dependência tende a diminuir. É na segunda fase que se observa o fenômeno cunhado "bônus demográfico", caracterizado pela mais baixa razão de pessoas inativas (crianças e idosos) em relação àquelas em idade potencialmente ativa. Por fim, as taxas de mortalidade e fecundidade se estabilizam em níveis baixos, causando estagnação ou até mesmo queda da taxa de crescimento populacional. A terceira fase é caracterizada pelo envelhecimento da população, com consequente aumento da razão de dependência, desta vez, impulsionada pela elevada participação dos idosos (ALVES, 2002; PAIVA; WAJNMAN, 2005; VASCONCELOS; GOMES, 2012). 
Existem grandes similaridades do exposto na teoria com o que se observa empiricamente no Brasil e em suas cinco regiões, como pode ser visto no Gráfico 1. Na década de 1960, as razões de dependência eram elevadas, variando entre $77,10 \%$ (Sudeste) e $94,80 \%$ (Norte). Em todos os casos, isso devia-se a uma expressiva RD infantil, que representava mais de $90 \%$ da RD total. Ao longo das décadas seguinte, em função exclusivamente da queda na RD infantil, houve uma expressiva redução da RD total. Apenas na região Sul a RD total já atingiu seu valor mínimo, em 2010. Nas demais isso ocorrerá em 2020 (Nordeste, Sudeste e Centro-Oeste) e em 2030 (Norte). Um padrão observado em todas as regiões é o envelhecimento da população ao longo das décadas, refletido pela elevação da RD de idosos e do índice de idosos.

Ainda, pode-se destacar que, no Norte e Nordeste, as razões de dependência eram muito maiores nos períodos pré-transição, reduzindo-se muito mais rapidamente a partir da década de 1990, aspectos que já haviam sido destacados no estudo de Potter et al. (2010). A diferença tanto no momento em que a transição ocorre quanto na velocidade da mesma gera significativas alterações nas distribuições etárias entre estados e municípios, podendo impactar de maneira diversificada no crescimento econômico das regiões (AMARAL et al., 2013; LIAO, 2011).

Prskawetz et al. (2007) destacam que, na primeira e terceira fases da transição demográfica, há uma "carga demográfica”, enquanto na segunda existe um “dividendo demográfico". Neste, há oportunidades para crescimento econômico, que são geradas principalmente por duas razões. Por um lado, tem-se o efeito contábil, ou seja, o diferencial entre o crescimento da força de trabalho e da população em geral, que tende a aumentar a razão entre a oferta e a demanda da economia. Por outro lado, há o efeito comportamental sobre a produtividade dos trabalhadores, que também tende a se expandir.

A literatura destacava que as características demográficas favoráveis teriam um efeito puramente transitório, ou seja, teriam impacto sobre o crescimento apenas no momento em que a força de trabalho aumentasse a uma taxa maior do que a população total (FUKUDA; MOROZUMI, 2004). Contudo, mais recentemente, o período que caracteriza o dividendo demográfico foi segmentado em primeiro e segundo dividendos (BAERLOCHER; PARENTE; RIOS-NETO, 2019).

O primeiro dividendo demográfico é transitório e está relacionado com o efeito contábil acima mencionado. Tendo em vista que a literatura indica que o impacto da estrutura etária sobre o crescimento econômico pode ser maior quando a qualidade das instituições é melhor, quando as economias são mais abertas e quando possuem uma regulamentação mais flexível do mercado de trabalho (BLOOM; CANNING; SEVILLA, 2003; FENT; MAHLBERG; PRSKAWETZ, 2008), dependendo também de boas políticas em diversas áreas, tais como saúde, educação, planejamento familiar (LIAO, 2011), este é um período bastante favorável para a realização de reformas estruturais (BLOOM; CANNING; FINK, 2010). Estimativas de Queiroz e Turra (2010) indicam que o Brasil ainda pode tirar vantagens referentes ao primeiro dividendo demográfico até 2025. Os autores destacam, por outro lado, que o 
ambiente macroeconômico e institucional não favoreceu os ganhos do bônus demográfico considerando o período de 1970 a 2010.

\section{GRÁFICO 1}

Razões de dependência total, infantil e de idosos e índice de idosos

Brasil e regiões geográficas - 1960-2060
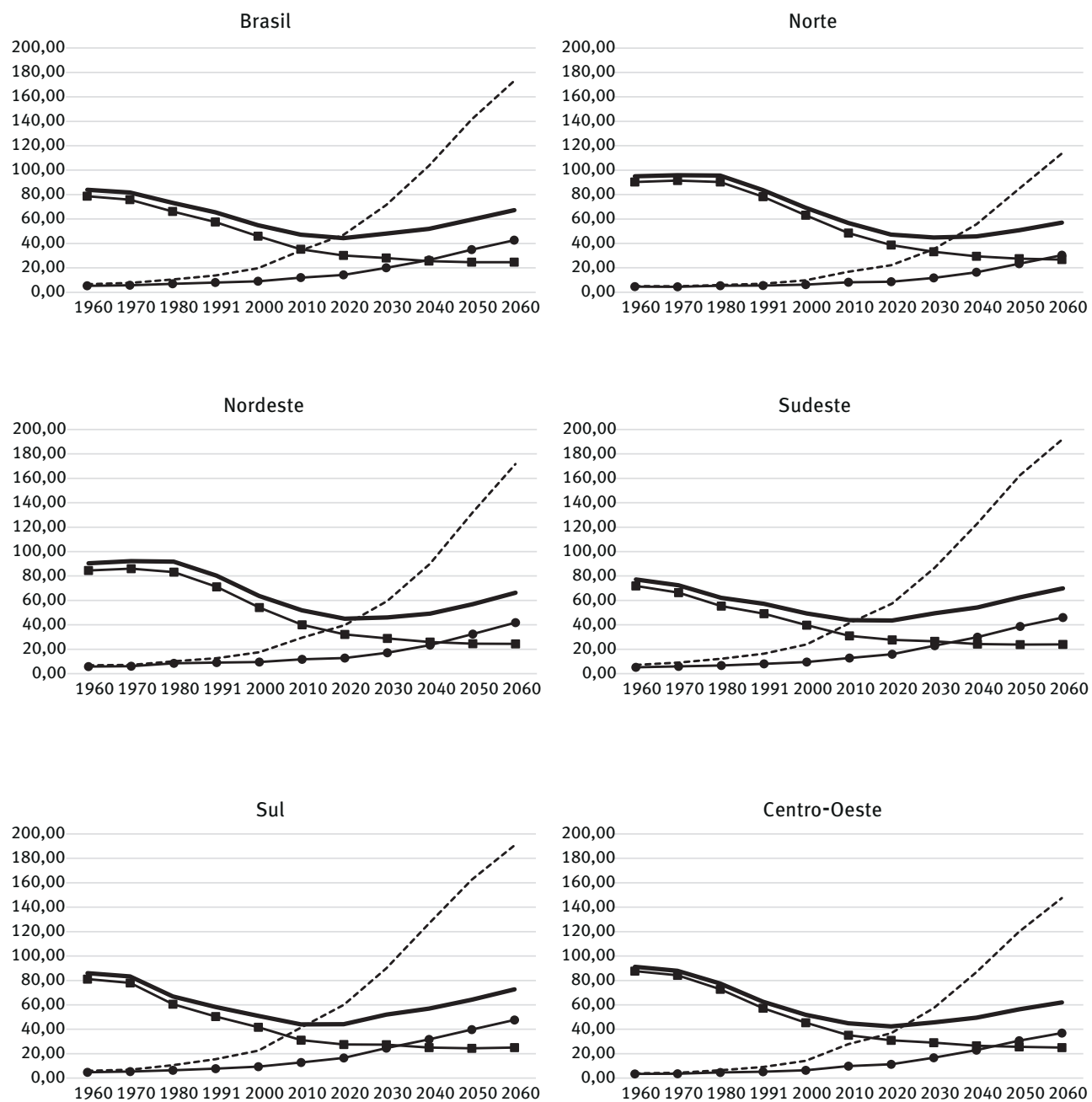

RD total

$\rightarrow-R D$ infantil

RD idosos

-.-- Índice de idosos

Fonte: IBGE. Censos Demográficos 1960 a 2010. Projeções Populacionais. Elaboração dos autores.

Nota: $R D$ total $=($ pessoas de 0 a 14 anos + pessoas de 65 anos ou mais) $/($ pessoas entre 15 e 64 anos)* 100 . RD infantil $=($ pessoas de 0 a 14 anos)/(pessoas entre 15 e 64 anos)*100. RD Idosos $=\left(\right.$ pessoas de 65 anos ou mais)/(pessoas entre 15 e 64 anos) ${ }^{\star} 100$ Índice de Idosos = (pessoas de 65 anos ou mais) $/($ pessoas de 0 a 14 anos $) \star 100$. 
Já o segundo dividendo demográfico é permanente e está relacionado com a criação de riqueza em razão do envelhecimento da população, uma vez que a acumulação de capital e as transferências são os elementos que sustentam o consumo futuro quando a população envelhece. As políticas públicas, em especial as educacionais e as institucionais, exercem papel importante para que ocorram a acumulação de capital e, consequentemente, a geração de riqueza (QUEIROZ; TURRA, 2010). Assim, o envelhecimento populacional pode produzir um aumento permanente do capital, afetando os determinantes de crescimento de longo prazo (FUKUDA; MOROZUMI, 2004; MASON, 2005). A ideia é que o impacto negativo do envelhecimento da população sobre o crescimento pode ser dominado pelo impacto positivo deste movimento sobre a acumulação de capital.

Há uma vasta gama de estudos que tratam dos efeitos da transição demográfica sobre o crescimento econômico. Para destacar apenas alguns dos mais recentes, pode-se mencionar o estudo desenvolvido por Misra (2015) para os países da União Europeia e dos Brics. Para o caso do Brasil, especificamente, a autora destacou que o dividendo demográfico, por si só, não foi suficiente para impactar positivamente o crescimento e atribuiu este resultado, em parte, ao insipiente desenvolvimento de setores importantes, bem como ao baixo incentivo para geração de poupança por parte das famílias - consequência do sistema previdenciário adotado no país.

Outras pesquisas destacam o papel da transição educacional sobre o crescimento, ocorrida no Brasil em paralelo com a transição demográfica. Amaral (2012), usando dados dos Censos brasileiros de 1960 a 2000, segmentou a força de trabalho masculina em 12 grupos de idade-escolaridade, mostrando que os tamanhos das coortes têm um impacto negativo sobre os ganhos. 0 autor argumenta que o fator de produtividade da mão de obra pode ser afetado pela mudança na estrutura etária, o que se relaciona com o segundo dividendo demográfico. Mudanças na idade e nas estruturas educacionais podem influenciar exogenamente a produtividade, dependendo do formato da curva de demanda de trabalho para cada idade e fator de trabalho educacional. Ainda, o estudo destacou que a melhora educacional contribuiu para a redução das desigualdades. Cuaresma, Lutz e Sanderson (2014) investigaram, a partir de um painel de países, se o dividendo demográfico é, na verdade, um dividendo educacional e concluíram que a melhora na educação é o elemento-chave para explicar o crescimento da renda e o aumento da produtividade.

Em um estudo realizado para México e Brasil, Amaral, Queiroz e Calazans (2015) mostraram que ambas as transições estão correlacionadas com os ganhos e retornos da educação. Já Baerlocher, Parente e Rios-Negro (2019), com base em um painel de dados para as microrregiões brasileiras no período de 1970 e 2010, argumentam que, uma vez que as estimações sejam controladas pelo capital humano, as mudanças na estrutura etária têm apenas efeitos contábeis sobre o crescimento. Assim, os autores concluíram que há um segundo dividendo demográfico no país, associado à educação.

Para Paiva e Wanjman (2005), o aumento da população em idade ativa está positivamente relacionado com a formação de poupança e com a produtividade, com reflexos 
positivos sobre o crescimento. Por outro lado, a elevação da participação da população idosa tem uma relação negativa com essas variáveis. Pelo lado da poupança privada, por exemplo, é sabido que esta tende a ser consumida nessa fase da vida, uma vez que os indivíduos fazem uso desses recursos com vistas à manutenção de seu padrão de consumo.

Nesse sentido, outra dimensão importante na análise são as implicações no que tange aos gastos públicos. No primeiro dividendo demográfico, por exemplo, os governos podem se beneficiar do maior número de contribuintes (QUEIROZ; TURRA, 2010). Contudo, o processo de envelhecimento populacional tende a causar impactos sobre a rede de seguridade social, dado que duas das consequências são o aumento do pagamento de pensões e a expansão dos gastos com saúde para a terceira idade (PRSKAWETZ et al., 2007).

Entre os estudos recentes que investigam esse aspecto, pode ser destacado o de Queiroz e Turra (2010), que estimaram o dividendo público para o Brasil, dado pela mudança na razão entre os contribuintes efetivos e os beneficiários efetivos de transferências públicas, concluindo que este se tornou negativo a partir de 2005, em decorrência do aumento das transferências para a população idosa. De certo modo, isso corrobora o que já havia sido levantado por Wong e Carvalho (2006). Os autores destacam que os gastos públicos direcionados para a população idosa avançarão expressivamente ao longo das próximas décadas, podendo reduzir os recursos disponíveis para investimento nas camadas mais jovens.

Um dos riscos associados a este processo é a desaceleração do crescimento econômico à medida que a população envelhece. Conforme destacam Emerson e Knabb (2019), quando o sistema previdenciário é de repartição simples (pay-as-you-go), a magnitude da desaceleração econômica dependerá se as transferências adicionais aos idosos inviabilizam o investimento em gerações atuais e futuras, ou seja, da medida em que a formação de capital humano é afetada.

\section{Dados e estratégia empírica}

Para avaliar o impacto da estrutura etária sobre o crescimento da renda per capita das regiões do Brasil, foi estimado um modelo autorregressivo espacial (SAR) em dois estágios. Com informações de 1991, 2000 e 2010, construiu-se um painel de dados, em nível de Áreas Mínimas Comparáveis (AMC), de dois períodos, a saber, 1991 e 2000. As informações de 2010 serviram apenas para o cômputo da variação de algumas variáveis do modelo entre dois períodos ( $t$ e $t+1)$. Assim, a variável dependente e o emprego, colocado como variável explicativa, são tomados pela variação entre 1991 e 2000 e entre 2000 e 2010 e as demais variáveis explicativas são tomadas tendo como referência 1991 e 2000. Dessa forma, tem-se um painel de AMC formado com dados de 1991 e 2000.

Cabe uma observação quanto ao nível geográfico das unidades de investigação. Dado que o intuito é conduzir a análise em nível municipal e que houve expressiva expansão no número de municípios no Brasil, principalmente na década de 1990, adotou-se a compatibilização territorial via AMC, prática bastante comum em estudos empíricos que avaliam 
questões de crescimento e desenvolvimento regional para o Brasil (BAERLOCHER; PARENTE; RIOS-NETO, 2019). Assim, como pode ser visto na Tabela 1, fazendo-se a compatibilização no período aqui analisado, a região Norte possui 254 AMC, a Nordeste 1.452, a Sudeste 1.423, a Sul 782 e a Centro-Oeste 356.

Formalmente, a equação que se deseja estimar é a seguinte: $\Delta \ln Y_{m, t+1}=\alpha_{0}+\alpha_{1}$ RDInfantil $_{m, t}+\alpha_{2}$ RDIdosos $_{m, t}+p W \Delta \ln Y_{m, t+1}+\beta$ Ano_ $2000_{t}+\gamma_{s}+$ $+\theta \Delta \ln L_{m, t+1}+\phi^{\prime} Z_{m, t}+\varepsilon_{m, t+1}$

Com AMC indo de $m=1, \ldots, M$ e períodos de $t=1991,2000$. Tem-se que $\Delta \ln Y_{m, t+1}$ é a variação da renda per capita na AMC $m$ entre os anos $t$ e $t+1$ (ou seja, entre 1991 e 2000

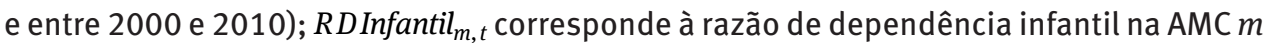
no ano $t ; R D I$ dosos $_{m, t}$ é a razão de dependência de idosos na AMC $m$ no ano $t ; p W \Delta \ln Y_{m, t+1}$ refere-se à defasagem espacial da variável dependente, sendo $W$ uma matriz de vizinhança do tipo contiguidade normalizada pela linha (Queen 13); Ano_2000 é uma dummy de ano, inserida no modelo para controlar eventos que possam ter afetado de maneira homogênea todas as observações em um dado período, assumindo valor zero para observações de 1991 e valor 1 para observações de 2000; $y_{s}$ corresponde a um vetor de dummies de estado, controlando as características não observáveis, mas invariantes ao longo do tempo, que são comuns entre todos as AMC do mesmo estado; $\Delta \ln L_{m, t+1}$ é a variação do emprego na AMC $m$ entre os anos $t$ e $t+1$, utilizada como uma covariada socioeconômica no modelo; $Z_{m, t}$ representa o conjunto das demais $k$ covariadas socioeconômicas da AMC $m$ no ano $t$, utilizadas na estimação com o objetivo de controlar características observáveis das AMC que podem se alterar ao longo do tempo; e $\varepsilon_{m, t+1}$ refere-se ao termo de erro.

Como já mencionado, a variável dependente aqui investigada $\left(\Delta \ln Y_{m, t+1}\right)$ é a variação da renda per capita domiciliar média das AMC. Esta desconta os efeitos da inflação, sendo apresentada, portanto, em termos reais. Pode ser entendida como uma medida de riqueza das localidades e foi calculada a partir dos dados disponibilizados pelos Censos Demográficos de 1991, 2000 e 2010 (IBGE). As variáveis demográficas (RDInfantil ${ }_{m, t}$ e RDIdosos $_{m, t}$ ) são as de interesse do estudo e também foram calculadas com base nos dados dos Censos.

Entre as covariadas socioeconômicas inseridas na regressão, está a variação do emprego ( $\Delta \ln L_{m, t+1}$ ), que foi obtida com base nos dados da Relação Anual de Informações Sociais (Rais, Ministério da Economia). ${ }^{4}$ A mesma é constituída pela mudança no número de trabalhadores formais em cada AMC nos períodos considerados na análise (entre 1991

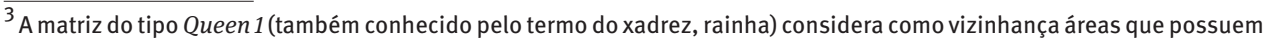
fronteira física com extensão diferente de zero e os vértices, de forma que 1 indica a ordem que está sendo considerada, ou seja, os vizinhos diretos da região (ALMEIDA, 2012).

${ }^{4}$ Não foi possível usar os dados dos Censos Demográficos para a construção desta variável, uma vez que as informações acerca de mercado de trabalho do Censo de 1991 não são comparáveis com aquelas trazidas pelos Censos de 2000 e 2010. Na edição de 1991, a construção das variáveis de mercado de trabalho - como ocupação, mão de obra empregada considera como período de referência os 12 meses anteriores à aplicação dos questionários. Nas edições de 2000 e 2010, por outro lado, a construção dessas variáveis tem como período de referência a semana que antecede a aplicação dos questionários. Assim, as definições são diferentes e é impossível fazer a compatibilização das informações. A limitação dos dados da Rais repousa no fato de considerar apenas o trabalho formal.
} 
e 2000 e entre 2000 e 2010) e foi inserida no modelo tendo como base a literatura de crescimento e também os estudos que tratam dos impactos da estrutura etária sobre o desempenho econômico (por exemplo, AZZONI; SILVEIRA-NETO, 2005; AMARAL; QUEIROZ; CALAZANS, 2015; BAERLOCHER; PARENTE; RIOS-NETO, 2019).

$O$ vetor $Z_{m, t}$ representa, de maneira compactada, as demais covariadas socioeconômicas inseridas na regressão. Este contém a renda per capita (em escala logarítmica), que objetiva controlar a regressão pelo nível inicial de riqueza de cada localidade, tendo sido calculada a partir das informações disponibilizadas nos Censos Demográficos. Diversos estudos dedicados à temática de crescimento destacam a importância do uso desta variável entre as explicativas, em especial aqueles voltados à análise da convergência de renda (por exemplo, GUIMARÃES; ALMEIDA, 2017).

$O$ vetor $Z_{m, t}$ também contém os anos médios de estudo da população com 25 anos de idade ou mais, calculados com base nos dados dos Censos Demográficos. É importante destacar que a acumulação de capital humano via aquisição de educação formal é amplamente reconhecida na literatura como um importante determinante no entendimento das questões relacionadas ao crescimento regional (por exemplo, ACEMOGLU; DELL, 2010; GENNAIOLI et al., 2014).

As demais covariadas socioeconômicas, extraídas dos Censos Demográficos de 1991 e 2000, são o percentual de pessoas residindo em domicílios situados em área urbana, com água canalizada e energia elétrica, a proporção de homens e brancos na população e a densidade demográfica - medida como habitantes por quilômetro quadrado. Por fim, também foi inserido o Índice de Desenvolvimento Humano (IDH) de longevidade, que é uma proxy das condições de saúde e de salubridade da população do município, extraído do Atlas do Desenvolvimento Humano de 2013.

A Tabela 1 traz as estatísticas descritivas da amostra, segmentadas por região. Pode-se observar que nas regiões Norte, Nordeste e Centro-Oeste houve aceleração da taxa de crescimento da renda per capita entre os períodos considerados. No Sudeste ocorreu desaceleração e no Sul houve estabilidade do crescimento. As variáveis demográficas, quando mensuradas a partir da média das AMC, apresentam a mesma dinâmica já discutida a partir dos dados do Gráfico 1.

A taxa de crescimento do emprego é positiva para todas as regiões e períodos considerados, tendo se acelerado nas regiões Norte e Nordeste e se desacelerado nas demais. Os anos de estudo aumentaram entre 1991 e 2000, sem exceções, em todas as coortes investigadas. A população masculina representa cerca de $50 \%$ do total, com pequenas variações entre as regiões e períodos, e a população branca é mais representativa no Sudeste e Sul. Entre 1991 e 2000, aumentou o percentual de pessoas vivendo em domicílios situados em área urbana, com água canalizada e energia elétrica. A densidade demográfica também se expandiu entre 1991 e 2000 em todas as regiões. A longevidade melhorou, sem exceções. As diferenças nos níveis das variáveis investigadas evidenciam as disparidades existentes ao longo do território nacional. 
TABELA 1

Estatísticas descritivas da amostra Regiões geográficas do Brasil - 1991-2000

\begin{tabular}{|c|c|c|c|c|c|c|c|c|c|c|}
\hline \multirow{3}{*}{ Variáveis } & \multicolumn{3}{|c|}{1991} & \multicolumn{2}{|c|}{2000} & \multicolumn{3}{|c|}{1991} & \multicolumn{2}{|c|}{2000} \\
\hline & Obs. & Média & DP & Média & DP & Obs. & Média & DP & Média & DP \\
\hline & \multicolumn{5}{|c|}{ Norte } & \multicolumn{5}{|c|}{ Nordeste } \\
\hline Var. da renda per capita (1) & 254 & 0,30 & 0,33 & 0,45 & 0,31 & 1.452 & 0,47 & 0,32 & 0,67 & 0,29 \\
\hline RD infantil & 254 & 90,80 & 15,68 & 75,56 & 16,38 & 1.452 & 81,47 & 11,11 & 62,12 & 9,99 \\
\hline RD idosos & 254 & 6,60 & 2,65 & 7,05 & 2,27 & 1.452 & 10,43 & 2,86 & 10,82 & 2,81 \\
\hline Var. do emprego formal (1) & 254 & 3,14 & 34,99 & 19,33 & 68,36 & 1.452 & 2,43 & 28,89 & 4,72 & 30,78 \\
\hline Renda per capita (In) & 254 & 5,15 & 0,39 & 5,39 & 0,42 & 1.452 & 4,75 & 0,35 & 5,12 & 0,33 \\
\hline Anos de estudo & 254 & 2,58 & 0,97 & 3,55 & 1,02 & 1.452 & 2,01 & 0,83 & 2,90 & 0,90 \\
\hline \% de dom. em área urbana & 254 & 44,89 & 19,61 & 52,95 & 19,38 & 1.452 & 41,91 & 20,31 & 49,67 & 19,72 \\
\hline$\%$ de homens & 254 & 51,81 & 1,51 & 52,13 & 1,40 & 1.452 & 49,99 & 1,44 & 50,22 & 1,36 \\
\hline$\%$ de brancos & 254 & 18,95 & 11,88 & 24,26 & 10,44 & 1.452 & 26,15 & 14,07 & 32,33 & 12,52 \\
\hline \% de dom. com água canal. & 254 & 21,50 & 15,28 & 33,99 & 17,61 & 1.452 & 26,95 & 17,77 & 41,87 & 18,71 \\
\hline \% de dom. com energia elet. & 254 & 46,24 & 19,69 & 65,40 & 17,28 & 1.452 & 54,87 & 21,04 & 78,55 & 17,24 \\
\hline Densidade demográfica & 254 & 18,55 & 103,24 & 24,62 & 150,53 & 1.452 & 84,35 & 406,50 & 96,19 & 466,57 \\
\hline \multirow[t]{2}{*}{ IDH-Longevidade } & 254 & 0,61 & 0,04 & 0,69 & 0,03 & 1.452 & 0,56 & 0,05 & 0,66 & 0,04 \\
\hline & \multicolumn{5}{|c|}{ Sudeste } & \multicolumn{5}{|c|}{ Sul } \\
\hline Var. da renda per capita (1) & 1.423 & 0,47 & 0,32 & 0,39 & 0,25 & 782 & 0,55 & 0,35 & 0,55 & 0,29 \\
\hline RD infantil & 1.423 & 56,35 & 11,25 & 44,98 & 8,46 & 782 & 53,52 & 8,07 & 43,82 & 7,11 \\
\hline RD idosos & 1.423 & 9,05 & 2,46 & 10,67 & 2,85 & 782 & 8,14 & 2,34 & 10,37 & 2,82 \\
\hline Var. do emprego formal (1) & 1.423 & 5,35 & 56,69 & 1,02 & 2,26 & 782 & 2,72 & 15,67 & 0,81 & 0,61 \\
\hline Renda per capita (In) & 1.423 & 5,68 & 0,48 & 6,04 & 0,41 & 782 & 5,71 & 0,34 & 6,12 & 0,31 \\
\hline Anos de estudo & 1.423 & 3,80 & 1,02 & 4,77 & 1,07 & 782 & 4,03 & 0,84 & 4,95 & 0,83 \\
\hline \% de dom. em área urbana & 1.423 & 63,15 & 22,28 & 69,61 & 20,33 & 782 & 51,07 & 23,34 & 59,66 & 21,77 \\
\hline$\%$ de homens & 1.423 & 50,83 & 1,53 & 50,58 & 1,50 & 782 & 50,73 & 1,30 & 50,45 & 1,30 \\
\hline$\%$ de brancos & 1.423 & 63,13 & 21,83 & 63,62 & 19,21 & 782 & 81,71 & 13,03 & 83,30 & 11,32 \\
\hline \% de dom. com água canal. & 1.423 & 77,85 & 19,92 & 90,49 & 13,61 & 782 & 80,21 & 14,66 & 93,14 & 7,18 \\
\hline \% de dom. com energia elet. & 1.423 & 85,23 & 17,95 & 95,45 & 8,11 & 782 & 87,61 & 13,32 & 96,50 & 5,35 \\
\hline Densidade demográfica & 1.423 & 153,91 & 775,60 & 182,91 & 879,95 & 782 & 69,24 & 227,42 & 81,33 & 275,25 \\
\hline IDH-Longevidade & 1.423 & 0,70 & 0,04 & 0,77 & 0,04 & 782 & 0,71 & 0,04 & 0,78 & 0,04 \\
\hline \multicolumn{11}{|c|}{ Centro-Oeste } \\
\hline Var. da renda per capita (1) & 356 & 0,43 & 0,32 & 0,49 & 0,28 & & & & & \\
\hline RD infantil & 356 & 61,37 & 9,93 & 48,09 & 7,83 & & & & & \\
\hline RD idosos & 356 & 6,09 & 2,10 & 8,07 & 2,64 & & & & & \\
\hline Var. do emprego formal (1) & 356 & 5,86 & 74,92 & 1,67 & 4,07 & & & & & \\
\hline Renda per capita (In) & 356 & 5,64 & 0,32 & 5,98 & 0,31 & & & & & \\
\hline Anos de estudo & 356 & 3,48 & 0,78 & 4,44 & 0,78 & & & & & \\
\hline \% de dom. em área urbana & 356 & 60,64 & 18,43 & 69,35 & 16,40 & & & & & \\
\hline$\%$ de homens & 356 & 51,96 & 1,82 & 51,59 & 1,63 & & & & & \\
\hline$\%$ de brancos & 356 & 45,82 & 16,17 & 49,35 & 13,63 & & & & & \\
\hline \% de dom. com água canal. & 356 & 57,34 & 18,08 & 80,54 & 15,35 & & & & & \\
\hline \% de dom. com energia elet. & 356 & 72,67 & 18,10 & 90,55 & 10,96 & & & & & \\
\hline Densidade demográfica & 356 & 14,39 & 45,21 & 18,34 & 73,10 & & & & & \\
\hline IDH-Longevidade & 356 & 0,67 & 0,03 & 0,75 & 0,03 & & & & & \\
\hline
\end{tabular}

Fonte: IBGE. Censos Demográficos. Elaboração dos autores.

(1) Taxa de crescimento. Para 1991, reporta o crescimento da variável entre 1991 e 2000. Para 2000, reporta o crescimento da variável entre 2000 e 2010. As demais estatísticas são apresentadas em nível para 1991 e 2000. 
Quatro observações são pertinentes a respeito do modelo estimado. Primeiramente, cabe destacar que o modelo estimado tem como base o proposto por Barreto, Almeida e De Lima (2010), adaptando-o para a temática do presente estudo. Nesse sentido, as variáveis demográficas, ou seja, as razões de dependência infantil e de idosos, foram inseridas tendo como base os estudos de Kelley e Schmidt (2005), Prskawetz et al. (2007) e De Santana Vasconcelos, Alves e Da Silveira Filho (2008).

A segunda observação refere-se à especificação do modelo. Como já mencionado na introdução deste texto, a inserção da defasagem espacial da variável dependente entre as variáveis explicativas, ou seja, a opção pela especificação do modelo como autorregressivo espacial (SAR), tem como base o avanço recente da literatura de crescimento econômico regional, que tem destacado a necessidade de corrigir adequadamente as correlações espaciais ao tratar desta temática. Na próxima seção, é feita uma análise exploratória dos dados espaciais para a variável dependente, de modo a explicitar a necessidade dessa correção.

A terceira observação está relacionada com a escolha pela estimação do modelo em dois estágios. Conforme visto anteriormente, uma das covariadas socioeconômicas presentes na equação (1) é a média dos anos de estudo das pessoas com 25 anos de idade ou mais, entendida no presente contexto como uma proxy do capital humano dos municípios. Como já destacado por Amaral, Queiroz e Calazans (2015) e por Baerlocher, Parente e Rios-Neto (2019), é importante que se levem em conta os aspectos relacionados ao capital humano quando são analisados os impactos da estrutura etária sobre o desempenho econômico.

Contudo, é largamente documentada na literatura a existência de endogeneidade entre educação e renda (por exemplo, BARBOSA FILHO; PESSÔA, 2009; ACEMOGLU; GALLEGO; ROBINSON, 2014; NIQUITO; RIBEIRO; PORTUGAL, 2018). Ademais, a literatura acerca do uso de modelos econométricos espaciais destaca que pode haver simultaneidade entre a variável dependente e a variável dependente espacialmente defasada (ALMEIDA, 2012).

Para corrigir estes problemas, é importante que a variável explicativa que representa o capital humano e a variável dependente espacialmente defasada sejam instrumentalizadas. Assim, o modelo SAR descrito pela equação (1) foi estimado via mínimos quadrados em dois estágios espaciais (MQ2EE). Nessa abordagem, ambas as variáveis supracitadas são consideradas endógenas e instrumentalizadas pela defasagem espacial de todas as demais variáveis explicativas utilizadas no modelo (SHEHATA, 2016).

A quarta e última observação pertinente é que os erros foram estimados de forma robusta para corrigir o problema de heterocedasticidade. Os efeitos da estrutura etária sobre o desempenho econômico das regiões brasileiras são mostrados na seção de resultados e discussão.

\section{Análise exploratória de dados espaciais}

Ao se estimar um modelo é preciso garantir que os resultados obtidos sejam não viesados e eficientes. Para que isso seja atingido a partir do método de mínimos quadrados 
ordinários (MQO), algumas hipóteses simplificadoras são feitas, entre estas a de ausência de autocorrelação residual (o que inclui autocorrelação espacial). Desse modo, é importante testar, diagnosticar e, se necessário, corrigir a presença de autocorrelação espacial.

Esta seção apresenta uma análise exploratória de dados espaciais para a variação da renda per capita. 0 intuito dessa investigação inicial é ratificar que a escolha do modelo apresentado na equação (1) foi apropriada. Em outras palavras, o objetivo é mostrar que há correlação espacial na variável dependente, sendo necessária a estimação do modelo SAR, que corrige este problema ao inserir, entre as variáveis explicativas, a defasagem espacial da variável dependente.

Segmentando-se os dados para cada uma das cinco regiões brasileiras, foi calculado, para os dois períodos contemplados no painel, o I de Moran, que consiste em um coeficiente de autocorrelação espacial global entre a variável de interesse dos vizinhos a um município e ele mesmo. Além disso, também foi calculada uma medida local de associação espacial, o Índice Univariado Local I de Moran (LISA), por meio do qual é possível identificar clusters regionais.

Os resultados são apresentados na Figura 1, que traz, para cada região e período, a estatística I de Moran e os mapas que mostram a associação espacial local. Nos mapas, é possível verificar a existência de clusters regionais do tipo alto-alto - quando locais com alto crescimento se avizinham de locais com alto crescimento -, baixo-baixo - locais com baixo crescimento se avizinham de locais com baixo crescimento -, alto-baixo - locais com alto crescimento se avizinham de locais com baixo crescimento - e baixo-alto - locais com baixo crescimento se avizinham de locais com alto crescimento. Nessas análises, assim como na estimação do modelo principal, foi empregada a matriz de ponderação espacial do tipo Queen 1.

Verifica-se, para todas as regiões, a partir da estatística I de Moran, que a hipótese nula de não existência de autocorrelação espacial da variável de interesse é rejeitada. Ainda, os mapas mostram a existência de clusters em todas as regiões e em ambos os períodos analisados. Na região Norte, entre 1991 e 2000, nota-se a presença de clusters principalmente dos tipos alto-alto (Rondônia e Tocantins) e baixo-baixo (majoritariamente no Amazonas). Já entre 2000 e 2010, os clusters principalmente do tipo alto-alto estão concentrados no Tocantins e no Acre e os do tipo baixo-baixo em Roraima e no Pará. No Nordeste, em ambos os períodos, diversos clusters são visualizados ao longo de todo território. No Sudeste, para os dois períodos analisados, os clusters do tipo alto-alto estão majoritariamente em Minas Gerais e os do tipo baixo-baixo em São Paulo. Na região Sul, os clusters alto-alto concentram-se principalmente no Paraná e no oeste de Santa Catarina e os do tipo baixo-baixo encontram-se na metade sul do Rio Grande do Sul. Por fim, no Centro-Oeste, entre 1991 e 2000, não se verifica autocorrelação espacial global, como mostrado pela estatística I de Moran, e existem poucos clusters de autocorrelação espacial local. Contudo, para o período de 2000 a 2010, observam-se clusters do tipo alto-alto em Goiás e do tipo baixo-baixo no Mato Grosso. 
FIGURA 1

Estatística I-Moran e clusters da variação da renda per capita Regiões geográficas do Brasil - 1991-2010

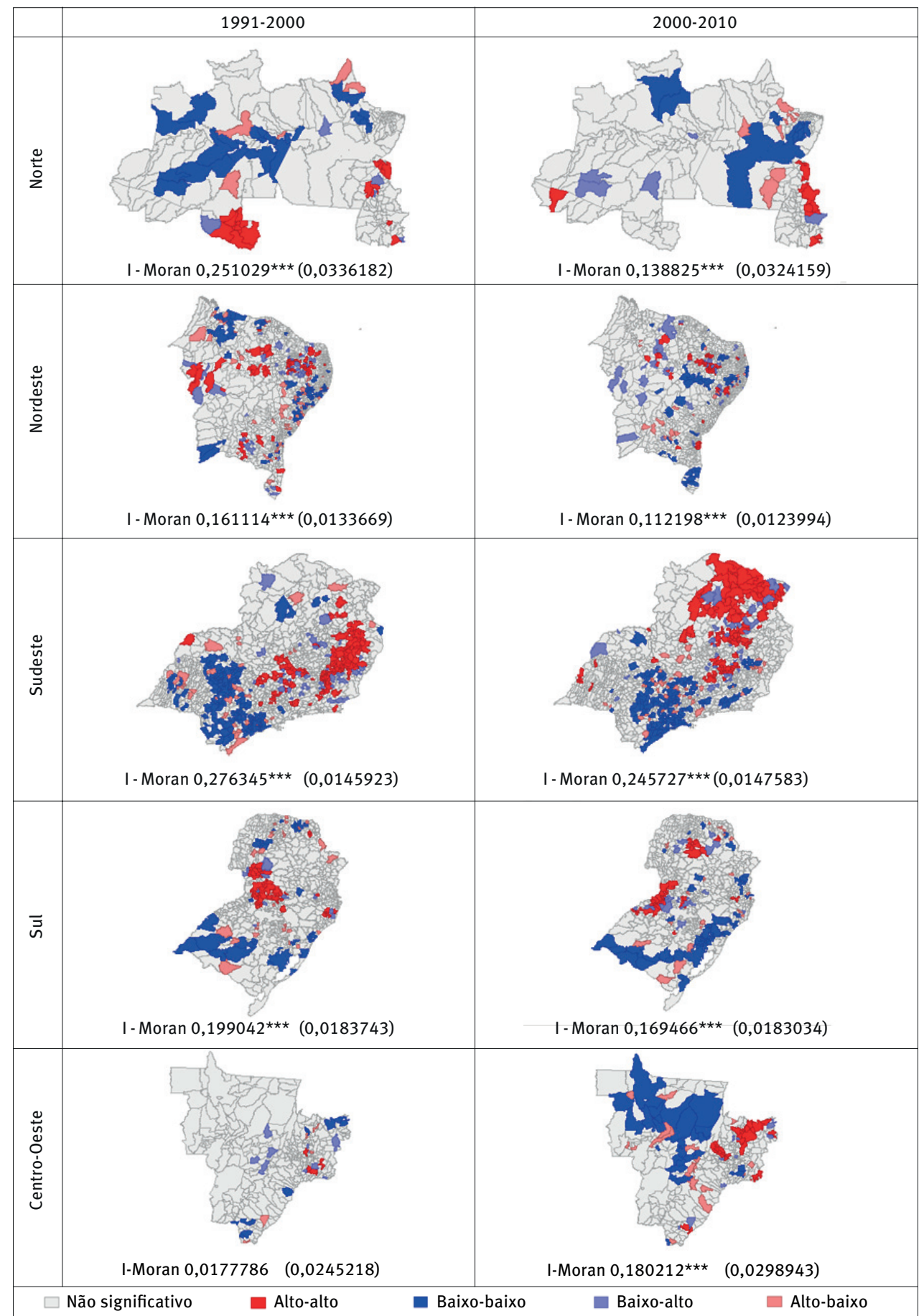

Fonte: IBGE. Censos Demográficos. Elaboração dos autores.

Nota: Os desvios padrões da estatística I de Moran encontram-se entre parênteses. Níveis de significância: ${ }^{*} p<0,10,{ }^{* \star} p<0,05,{ }^{\star * \star} p<0,01$. 
Os resultados apresentados evidenciam que há autocorrelação espacial na variável dependente nos períodos contemplados na análise. Desse modo, o uso da variável dependente defasada entre as variáveis explicativas é necessário para controlar esse problema. Os resultados estimados para o modelo SAR em dois estágios são discutidos na seção seguinte.

\section{Resultados e discussão}

Esta seção traz os resultados estimados acerca dos efeitos da estrutura etária sobre o crescimento da renda per capita para as cinco regiões do Brasil. Pela limitação de espaço, são apresentados apenas os coeficientes estimados para as variáveis demográficas aqui utilizadas, ou seja, as razões de dependência infantil e de idosos, uma vez que estas são o cerne do presente estudo. Em todos os casos, os modelos foram estimados com a defasagem espacial da variável dependente, com os efeitos fixos de ano e de estado e com as covariadas socioeconômicas, ${ }^{5}$ de acordo com o especificado na equação (1).

Ainda, conforme explicado na seção de dados e estratégia empírica, os resultados foram obtidos via estação por MQ2EE, no qual a covariada de capital humano e a defasagem espacial da variável dependente foram instrumentalizadas pela defasagem espacial das demais covariadas. Além dos coeficientes, a Tabela 2 também traz algumas estatísticas importantes para a análise da adequabilidade do modelo. Nesse sentido, são apresentados os níveis descritivos ( $p$-valores) do teste de Hausmann, que auxilia na verificação da consistência do modelo com instrumentos, ou seja, indica se a estimação com variáveis instrumentais é melhor do que aquela sem variáveis instrumentais, e do teste de Sargan, que auxilia na verificação da adequabilidade dos instrumentos utilizados, mostrando se eles são válidos e não correlacionados com o termo de erro.

Em relação ao impacto da razão de dependência infantil sobre a variação da renda per capita, destaca-se que em todas as regiões brasileiras os coeficientes estimados foram negativos e estatisticamente significativos, ratificando os resultados observados na literatura, como são exemplos os estudos de Fukuda e Morozumi (2004), Kelley e Schmidt (2005), Prskawetz et al. (2007) e Wongboonsin e Phiromswad (2017). Ainda, é importante ressaltar que os efeitos são maiores nas regiões menos desenvolvidas do país. No Norte, para cada 1 ponto percentual a mais na RD infantil no período inicial, a taxa de crescimento da renda per capita foi $0,511 \%$ menor. No Nordeste, a redução na taxa de crescimento da renda per capita foi de 0,493\%. Já nas regiões Centro-Oeste, Sul e Sudeste, os decréscimos, embora ainda presentes, são menores, de 0,360\%, 0,257\% e 0,209\%, respectivamente.

Por sua vez, no que tange ao impacto da razão de dependência de idosos sobre a variação da renda per capita, os resultados, quando estatisticamente significativos, também foram negativos. Assim como no caso da RD infantil, os efeitos foram mais expressivos nas regiões Norte e Nordeste. Na primeira, para cada 1 ponto percentual a mais na RD de idosos

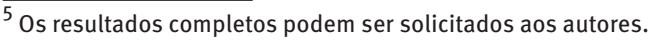


no período inicial, a taxa de crescimento da renda per capita foi $1,86 \%$ menor. Na segunda, o efeito é semelhante, indicando uma taxa de crescimento 1,05\% menor. No Centro-Oeste o efeito também foi estatisticamente significativo, sinalizando uma redução de $0,965 \%$ na taxa de crescimento. Por fim, nas regiões Sudeste e Sul os efeitos não se mostraram estatisticamente significativos, podendo ser um indicativo de que este é um problema mais latente em regiões menos desenvolvidas. Cabe ainda ressaltar que, em uma análise para os estados brasileiros, essa relação negativa também foi encontrada (PORSSE et al., 2012). Contudo, a literatura ainda não possui um consenso sobre o efeito da razão de dependência de idosos (FUKUDA; MOROZUMI, 2004). Conforme discutido anteriormente, caso o envelhecimento populacional seja acompanhado de um aumento permanente do estoque de capital, devido à elevação da taxa de poupança, os efeitos positivos deste movimento podem dominar os esperados efeitos negativos do envelhecimento sobre o crescimento.

Em todas as regiões, os níveis descritivos do teste de Hausman mostram que os modelos com instrumentos são mais adequados do que aqueles sem instrumentos, ou seja, a hipótese nula de que o modelo com variáveis instrumentais é consistente não é rejeitada. Ainda, também em todas as regiões, os níveis descritivos do teste de Sargan indicam que não se rejeita a hipótese nula de que os instrumentos são válidos e não correlacionados com o termo de erro. Ambos ratificam que a escolha da especificação do modelo é adequada.

Chama a atenção o fato de que, nas regiões em que o efeito da RD de idosos sobre a taxa de crescimento da renda per capita foi significativo, este foi consideravelmente mais expressivo do que aquele registrado para a RD infantil. No Norte, o impacto da primeira é 3,6 vezes superior em relação à segunda. No Nordeste e no Centro-Oeste, essa razão é de 2,1 e 2,7, respectivamente. Como apresentado no Gráfico 1, o processo de transição demográfica está em curso em todo o país, inclusive nessas regiões menos desenvolvidas. Nas próximas décadas, o número de idosos superará o de crianças, e os efeitos negativos sobre o desempenho econômico poderão se intensificar.

TABELA 2

Resultados para o efeito da estrutura etária sobre a renda per capita via estimação por mínimos quadrados em dois estágios espaciais (MQ2EE)

Regiões geográficas do Brasil - 1991/2010

\begin{tabular}{lrrrrr}
\hline \multicolumn{1}{c}{ Variáveis } & \multicolumn{1}{c}{ Norte } & Nordeste & \multicolumn{1}{c}{ Sudeste } & \multicolumn{1}{c}{ Sul } & Centro-Oeste \\
\hline RD infantil & $-0,00511^{\star \star \star}$ & $-0,00493^{\star \star \star}$ & $-0,00209^{\star}$ & $-0,00257^{\star \star \star}$ & $-0,00360^{\star \star \star}$ \\
& $(0,00178)$ & $(0,000905)$ & $(0,00116)$ & $(0,000771)$ & $(0,00136)$ \\
RD idosos & $-0,0186^{\star \star \star}$ & $-0,0105^{\star \star \star}$ & 0,000960 & 0,000578 & $-0,00965^{\star \star \star}$ \\
& $(0,00549)$ & $(0,00219)$ & $(0,00188)$ & $(0,00216)$ & $(0,00281)$ \\
Obs. & 508 & 2.904 & 2.846 & 1.564 & 712 \\
Testes & & & & & 1,0000 \\
Hausman (p-valor) & 1,0000 & 0,9994 & 0,9343 & 0,5848 & 0,2901 \\
Sargan (p-valor) & 0,6862 & 0,9599 & 0,1902 & 0,000 \\
\hline
\end{tabular}

Fonte: IBGE. Censos Demográficos. Elaboração dos autores.

Nota: Os desvios padrões encontram-se entre parênteses. Níveis de significância: ${ }^{*} p<0,10,{ }^{* \star} p<0,05,{ }^{\star \star \star} p<0,01$. 
Os resultados aqui encontrados são fortes indicativos de que a estrutura econômica necessitará se adaptar às mudanças observadas na estrutura etária, de modo a minimizar os potenciais impactos negativos advindos do envelhecimento populacional, com especial atenção às regiões menos desenvolvidas. É premente que sejam desenvolvidas diversas políticas públicas, visando enfrentar as várias facetas do desafio em questão. Nesse sentido, a Reforma da Previdência aprovada em 2019 parece ser um passo na direção correta. 0 estudo desenvolvido por Porsse et al. (2012), por exemplo, indica que o impacto do bônus demográfico sobre a taxa de crescimento da renda per capita é positivo, de forma que aumentar o período de contribuição pode ser uma alternativa ao efeito negativo da razão de dependência de idosos.

Outro enfoque que encontra respaldo na literatura tem relação com as políticas educacionais que visem minorar os efeitos do envelhecimento populacional sobre o crescimento econômico (FOUGÈRE et al., 2009; FOUGÈRE; MÉRETTE, 1999; SADAHIRO; SHIMASAWA, 2003). É possível que o impacto negativo esteja associado aos baixos índices educacionais no Brasil, o que reforça a necessidade de uma mudança imediata para reverter esse quadro. 0 capital humano, por meio da educação, pode contribuir tanto para o primeiro dividendo demográfico, uma vez que quanto mais qualificadas as pessoas em idade ativa maior tendem a ser sua produtividade e, consequentemente, o crescimento econômico, como para o segundo dividendo demográfico, pois contribui positivamente para a acumulação de capital. Políticas de capacitação técnica para as gerações mais velhas também devem ser consideradas, principalmente tendo em vista que os impactos negativos parecem ser mais intensos em regiões menos desenvolvidas. Esse comportamento pode, por exemplo, ser reflexo de uma estrutura econômica mais concentrada em setores intensivos em mão de obra.

Entre as políticas públicas que podem contribuir para mitigar o impacto negativo do envelhecimento populacional sobre o crescimento da renda per capita também estão aquelas relacionadas a mudanças na regulamentação e à flexibilização do mercado de trabalho, com vistas, por exemplo, a aumentar a participação de mulheres e de idosos na população ocupada. Barbosa (2014) mostra que a participação da mulher no mercado de trabalho brasileiro contribui para o aumento da oferta de trabalho, o que pode diminuir os efeitos negativos causados pelo envelhecimento populacional. Damaceno e Chirelli (2019), por sua vez, salientam a importância de estratégias em saúde na família voltadas para idosos e ressaltam a necessidade de fortalecer as ações direcionadas para a cogestão, ações intersetoriais e formação profissional alinhada a novas práticas e tecnologias que possam atender às necessidades da população idosa. 


\section{Considerações finais}

Este estudo buscou avaliar o impacto da razão de dependência infantil e de idosos sobre o crescimento da renda per capita das Áreas Mínimas Comparáveis (AMC), segmentando a análise para cada uma das cinco regiões brasileiras. 0 estudo considerou o período entre 1991 e 2010 e a estratégia empírica adotada foi a estimação modelo autorregressivo espacial pelo método de mínimos quadrados em dois estágios.

A análise exploratória espacial para a variação da renda per capita corroborou o consenso que vem se formando recentemente na literatura, de que, quando se trata de questões relacionadas ao crescimento regional, há que se levar em conta a presença de autocorrelação espacial. Este fator, somado à possível simultaneidade entre a variável dependente e a variável dependente espacialmente defasada e à reconhecida endogeneidade de uma das covariadas presentes no modelo, a saber, educação, justificou a escolha da especificação adotada na estimação.

Os resultados obtidos neste estudo indicam que a RD infantil impactou negativamente o crescimento da renda em todas as regiões do país. Ainda, estes efeitos foram mais expressivos nas regiões menos desenvolvidas. No caso do impacto da RD de idosos, os coeficientes se mostraram significativos apenas no Norte, Nordeste e Centro-Oeste, o que pode ser um indicativo de que o envelhecimento populacional afeta mais intensamente as localidades mais vulneráveis em termos de desenvolvimento. Ainda, cabe ressaltar que, quando estatisticamente significativos, os efeitos negativos da RD de idosos se mostraram de duas a quatro vezes superiores aos efeitos negativos da RD infantil.

As consequências do envelhecimento populacional são potencialmente nocivas para as economias locais. 0 necessário aumento de gastos com saúde e com o sistema de seguridade social pode reduzir a quantidade de recursos disponíveis para investimentos nas coortes populacionais mais jovens, com potenciais efeitos negativos no crescimento de longo prazo. Assim, é necessário que seja desenvolvido um conjunto de políticas públicas que visem mitigar os efeitos da transição demográfica. Entre elas, destacam-se ajustes do sistema previdenciário, para que se reduza o impacto sobre as contas públicas, investimentos em formação de capital humano e na capacitação da mão de obra, com vistas a aumentar a produtividade, e melhora na regulamentação do mercado de trabalho, que permita, por exemplo, o aumento da participação das mulheres e das pessoas idosas na força de trabalho.

Alguns aspectos têm sido debatidos na literatura acerca dos impactos das mudanças demográficas sobre o desempenho econômico, tais como o canal de transmissão dos efeitos via poupança e também sobre a realocação dos gastos públicos que, como mencionado acima, com o envelhecimento populacional, podem ser redirecionados das coortes mais jovens da população para as de idade mais avançada, impactando negativamente o crescimento de longo prazo. Conduzir tais investigações para o Brasil em nível municipal é um desafio, devido à escassez de dados, e são deixadas como sugestões para estudos futuros, visando o avanço da discussão. 


\section{Referências}

ACEMOGLU, D.; DELL, M. Productivity differences between and within countries. American Economic Journal: Macroeconomics, v. 2, n. 1, p. 169-88, 2010.

ACEMOGLU, D.; GALLEGO, F. A.; ROBINSON, J. A. Institutions, human capital, and development. Annual Review of Economics, v. 6, n. 1, p. 875-912, 2014.

ALMEIDA, E. Econometria espacial. Campinas-SP: Alínea, 2012.

ALVES, J. E. D. A polêmica Malthus versus Condorcet reavaliada à luz da transição demográfica. Rio de Janeiro: IBGE/Escola Nacional de Ciências Estatísticas, 2002. (Texto para Discussão, n. 4).

ALVES, J. E. D. A transição demográfica e a janela de oportunidade. São Paulo: Instituto Fernand Braudel de Economia Mundial, 2008.

AMARAL, E. F. L. The decomposition of economic outcomes as a result of changes in Brazil's male age-education structure. Population Research and Policy Review, v. 31, n. 6, p. 883-905, 2012.

AMARAL, E. F. L. et al. Age, education, and earnings in the course of Brazilian development: does composition matter? Demographic Research, v. 28, n. 20, p. 581-612, 2013.

AMARAL, E. F. L.; QUEIROZ, B. L.; CALAZANS, J. A. Demographic changes, educational improvements, and earnings in Brazil and Mexico. IZA Journal of Labor \& Development, v. 4, n. 1, p. 23-29 dez. 2015.

AZZONI, C. R.; SILVEIRA-NETO, R. M. Decomposing regional growth: labor force participation rates, structural changes, and sectoral factor reallocation. The Annals of Regional Science, v. 39, n. 2, p. 221-239, 2005.

BAERLOCHER, D.; PARENTE, S. L.; RIOS-NETO, E. Economic effects of demographic dividend in Brazilian regions. The Journal of the Economics of Ageing, v. 14, p. 100-198, 2019.

BARBOSA, A. L. N. de H. Participação feminina no mercado de trabalho brasileiro. Mercado de Trabalho: conjuntura e análise, n. 57, p. 31-41, 2014.

BARBOSA FILHO, F. de H.; PESSÔA, S. Educação, crescimento e distribuição de renda: a experiência brasileira em perspectiva histórica. In: VELOSO, F.; PESSÔA, S.; HENRIQUES, R.; GIAMBIAGI, F. (org.). Educação básica no Brasil: construindo o país do futuro. Rio de Janeiro: Campus/Elsevier, 2009. p. 51-72.

BARRETO, R. C. S.; ALMEIDA, E. S.; DE LIMA, J. E. Convergência espacial do PIB per capita no estado do Ceará. Revista de Economia, v. 36, n. 3, 2010.

BECKER, S. O.; CINNIRELLA, F.; WOESSMANN, L. The trade-off between fertility and education: evidence from before the demographic transition. Journal of Economic Growth, v. 15, n. 3, p. 177-204, 2010.

BLOOM, D.; CANNING, D.; SEVILLA, J. The demographic dividend: a new perspective on the economic consequences of population change. [S.I.]: Rand Corporation, 2003.

BLOOM, D. E.; CANNING, D.; FINK, G. Implications of population ageing for economic growth. Oxford Review of Economic Policy, v. 26, n. 4, p. 583-612, 2010.

BRITO, F. Transição demográfica e desigualdades sociais no Brasil. Revista Brasileira de Estudos de População, v. 25, n. 1, p. 5-26, 2008.

CAPELLO, R. Spatial spillovers and regional growth: a cognitive approach. European Planning Studies, v. 17, n. 5, p. 639-658, 2009. 
CUARESMA, J. C.; LUTZ, W.; SANDERSON, W. Is the demographic dividend an education dividend? Demography, v. 51, n. 1, p. 299-315, 2014.

DAMACENO, M. J. C. F.; CHIRELLI, M. Q. Implementação da saúde do idoso na estratégia saúde da família: visão dos profissionais e gestores. Ciência \& Saúde Coletiva, v. 24, n. 5, p. 1637-1646, 2019.

DE SANTANA VASCONCELOS, D.; ALVES, J. E. D.; DA SILVEIRA FILHO, G. B. Crescimento econômico, estrutura etária e dividendo demográfico: avaliando a interação com dados em painel. In: XVI ENCONTRO NACIONAL DE ESTUDOS POPULACIONAIS. Anais [...]. Caxambu: Abep, 2008.

EMERSON, P.; KNABB, S. A demographic headwind: will an aging society reduce the real interest rate and potential growth? The Journal of the Economics of Ageing, p. 100-190, 2019.

FENT, T.; MAHLBERG, B.; PRSKAWETZ, A. Demographic change and economic growth. In: KOHLBACHER, F.; HERSTATT, C. (ed.). The silver market phenomenon. [S.l.]: Springer, 2008. p. 3-16.

FOUGÈRE, M. et al. Population ageing, time allocation and human capital: a general equilibrium analysis for Canada. Economic Modelling, v. 26, n. 1, p. 30-39, 2009.

FOUGÈRE, M.; MÉRETTE, M. Population ageing and economic growth in seven OECD countries. Economic Modelling, v. 16, n. 3, p. 411-427, 1999.

FUKUDA, S.; MOROZUMI, R. Economic growth under the demographic transition: a theory and some international evidence. In: ONOFRI, P. (ed.). The economics of an ageing population. [S.I.]: Edward Elgar, 2004. p. 3-34.

GALOR, O. The demographic transition: causes and consequences. Cliometrica, v. 6, n. 1, p. 1-28, 2012.

GALOR, O.; MOAV, O. Natural selection and the origin of economic growth. The Quarterly Journal of Economics, v. 117, n. 4, p. 1133-1191, 2002.

GENNAIOLI, N. et al. Growth in regions. Journal of Economic growth, v. 19, n. 3, p. 259-309, 2014.

GUIMARÃES, P. M.; ALMEIDA, E. A análise de convergência de renda no Brasil e o problema de escala espacial. Ensaios FEE, v. 37, n. 4, p. 899-924, 2017.

JONES, C.; VOLLRATH, D. Introdução à teoria do crescimento econômico. [S.I.]: Elsevier Brasil, 2016. v. 2

KELLEY, A. C.; SCHMIDT, R. M. Evolution of recent economic-demographic modeling: a synthesis. Journal of Population Economics, v. 18, n. 2, p. 275-300, 2005.

LESAGE, J. P.; FISCHER, M. M. Spatial growth regressions: model specification, estimation and interpretation. Spatial Economic Analysis, v. 3, n. 3, p. 275-304, 2008.

LIAO, P.-J. Does demographic change matter for growth? European Economic Review, v. 55, n. 5, p. 659-677, 2011.

LIMA, R. C. D. A.; SILVEIRA NETO, R. D. M. Physical and human capital and Brazilian regional growth: a spatial econometric approach for the period 1970-2010. Regional Studies, v. 50, n. 10, p. 1688-1701, 2016.

LIMA, R. C. de A.; BARBOSA, A. V. B. Natural disasters, economic growth and spatial spillovers: Evidence from a flash flood in Brazil. Papers in Regional Science, v. 98, n. 2, p. 905-924, 2019.

LUNDQUIST, J. H.; ANDERTON, D. L.; YAUKEY, D. Demography: the study of human population. [S.I.]: Waveland Press, 2014. 
MASON, A. Demographic transition and demographic dividends in developed and developing countries. United Nations expert group meeting on social and economic implications of changing population age structures. In: UNITED NATIONS EXPERT GROUP MEETING ON SOCIAL AND ECONOMIC IMPLICATIONS OF CHANGING POPULATION AGE STRUCTURES Proceedings [...]. Mexico City: United Nations, 2005.

MISRA, R. Impact of demographic dividend on economic growth: a study of BRICS and the EU. International Studies, v. 52, n. 1-4, p. 99-117, 2015.

NIQUITO, T. W.; RIBEIRO, F. G.; PORTUGAL, M. S. Institutions or human capital: which is more important for economic performance? Evidence from Brazil. Economics Bulletin, v. 38, n. 2, p. 1069-1076, 2018.

ÖZYURT, S.; DAUMAL, M. Trade openness and regional income spillovers in Brazil: a spatial econometric approach. Papers in Regional Science, v. 92, n. 1, p. 197-215, 2013.

PAIVA, P. de T. A.; WAJNMAN, S. Das causas às conseqüências econômicas da transição demográfica no Brasil. Revista Brasileira de Estudos de População, v. 22, n. 2, p. 303-322, 2005.

PORSSE, A. et al. Demographic change and regional economic growth in Brazil. São Paulo: Regional and Urban Economics Lab, University of São Paulo, 2012.

POTTER, J. E. et al. Mapping the timing, pace, and scale of the fertility transition in Brazil. Population and Development Review, v. 36, n. 2, p. 283-307, 2010.

PRSKAWETZ, A. et al. The relationship between demographic change and economic growth in the EU. Vienna: Institute of Demography, Austrian Academy of Sciences, 2007 (Research Report, 32).

QUEIROZ, B. L.; TURRA, C. M. Window of opportunity: socioeconomic consequences of demographic changes in Brazil. Washington, DC: NTA, 2010.

REIS, C.; BARBOSA, L. M. de L. H.; PIMENTEL, V. P. O desafio do envelhecimento populacional na perspectiva sistêmica da saúde. BNDES Setorial, n. 44, p. 87-124, 2016.

RESENDE, G. M. Multiple dimensions of regional economic growth: the Brazilian case, 1991- 2000. Papers in Regional Science, v. 90, n. 3, p. 629-662, 2011.

SADAHIRO, A.; SHIMASAWA, M. The computable overlapping generations model with an endogenous growth mechanism. Economic Modelling, v. 20, n. 1, p. 1-24, 2003.

SHEHATA, E. SPREGCS: Stata module econometric toolkit to estimate spatial cross section regression models. Boston: Boston College Department of Economics, 2016.

SILVEIRA NETO, R.; AZZONI, C. R. Location and regional income disparity dynamics: the Brazilian case. Papers in Regional Science, v. 85, n. 4, p. 599-613, 2006.

TEJADA, C. A. O. et al. The sociodemographic, behavioral, reproductive, and health factors associated with fertility in Brazil. PloS one, v. 12, n. 2, 2017.

VASCONCELOS, A. M. N.; GOMES, M. M. F. Transição demográfica: a experiência brasileira. Epidemiologia e Serviços de Saúde, v. 21, n. 4, p. 539-548, 2012.

WONG, L. L. R.; CARVALHO, J. A. O rápido processo de envelhecimento populacional do Brasil: sérios desafios para as políticas públicas. Revista Brasileira de Estudos de População, v. 23, n. 1, p. 5-26, 2006.

WONGBOONSIN, K.; PHIROMSWAD, P. Searching for empirical linkages between demographic structure and economic growth. Economic Modelling, v. 60, p. 364-379, 2017.

ZUANAZZI, P.; BANDEIRA, M.; STAMPE, M. Perfil demográfico do RS: evolução, tendência e impactos econômicos. In: MATTOS, E. J.; BAGOLIN, I. P. Desenvolvimento econômico no Rio Grande do Sul: já não somos o que éramos. Porto Alegre: Edipucrs, 2014. 


\title{
Sobre os autores
}

Marianne Zwilling Stampe é doutora em Economia pela Universidade Federal do Rio Grande do Sul. Professora adjunta na Universidade do Estado de Santa Catarina.

Fernando Pozzobon é mestre em Economia pela Universidade Federal de Pernambuco. Professor assistente na Universidade do Estado de Santa Catarina.

Thais Waideman Niquito é doutora em Economia pela Universidade Federal do Rio Grande do Sul. Professora adjunta na Universidade do Estado de Santa Catarina.

\section{Endereço para correspondência}

\author{
Marianne Zwilling Stampe \\ Departamento de Ciências Econômicas, Esag/Udesc \\ Av. Me. Benvenuta, 2037, Itacorubi \\ 88035-001 - Florianópolis-SC, Brasil \\ Fernando Pozzobon \\ Departamento de Ciências Econômicas, Esag/Udesc \\ Av. Me. Benvenuta, 2037, Itacorubi \\ 88035-001 - Florianópolis-SC, Brasil \\ Thais Waideman Niquito \\ Departamento de Ciências Econômicas, Esag/Udesc \\ Av. Me. Benvenuta, 2037, Itacorubi \\ 88035-001 - Florianópolis-SC, Brasil
}

\begin{abstract}
Impacts of the age structure on the economic performance of Brazilian regions between 1991 and 2010
\end{abstract}

This study aims to analyze how age structure affected the economic performance of Brazilian regions between the 1990s and 2010. For this research, information is mainly taken from that provided by the Brazilian Institute of Geography and Statistics (IBGE) through the 1991, 2000 and 2010 editions of the Demographic Census. The empirical strategy adopted consists of the estimation of a model of spatial autocorrelation by the two-stage least squares method. The results showed that both child and elderly dependency ratio have a negative impact on economic growth, with the effects being more pronounced in less developed regions. Still, it was found that, when significant, the effect of the elderly dependency ratio is more pronounced in relation to children.

Keywords: Demographic transition. Economic growth. Brazilian regions. 


\section{Resumen}

Impactos de la estructura de edad sobre el desempeño económico de las regiones brasileñas entre 1991 y 2010

Este estudio tiene como objetivo analizar cómo la estructura de edad afectó el desempeño económico de las regiones brasileñas desde la década del noventa hasta la primera del siglo xxı. Para la investigación propuesta, se utilizan principalmente las informaciones proporcionadas por el Instituto Brasileño de Geografía y Estadística (IBGE) a través de las ediciones de 1991, 2000 y 2010 del censo demográfico. La estrategia empírica adoptada consiste en la estimación de un modelo de autocorrelación espacial por el método de mínimos cuadrados en dos etapas. Los resultados mostraron que tanto el índice de dependencia infantil como el de ancianos tienen un impacto negativo en el crecimiento económico, y los efectos son más pronunciados en las regiones menos desarrolladas. Aun así, se encontró que, cuando es significativo, el efecto de la relación de dependencia de ancianos es más pronunciado en relación con los niños.

Palabras clave: Transición demográfica. Crecimiento económico. Regiones brasileñas.

Recebido para publicação em 16/04/2020 Aceito para publicação em 14/05/2020 